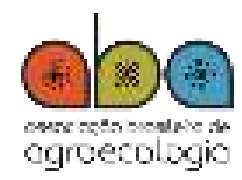

ISSN: $1980-9735$

\title{
EXPECTATIVAS E PERCEPÇÕES SOBRE OS IMPACTOS DA METODOLOGIA DE CONSTRUÇÃO DA CAPACIDADE CRIATIVA EM DUAS COMUNIDADES RURAIS
}

\author{
Expectations and perceptions on the impacts of creative capacity building approach
}

in two rural communities

\author{
Carolina Alzate Gouzy ${ }^{1}$; Cristiane Gomes Barreto²; Bárbara Salvio de Carvalho ${ }^{3}$; \\ Ricardo Gomes Ribeiro"; Odair Scatolini Junior ${ }^{5}$; Zaré Augusto Brum Soares ${ }^{6}$; \\ Juliana Ferreira de Assis ${ }^{7}$ e Marina Speroto Serra ${ }^{8}$
}

1 Universidade de Brasília, pesquisadora colaboradora.

mail: carolina.alzate@unb.br

2 Universidade de Brasilia, professora adjunta. E-mail: crisbarreto@unb.br

3 Universidade de Brasília, estudante. Email: barbarasalvio@aluno.unb.br

4 Universidade de Brasília, técnico. Email: ricardogomes@unb.br

5.Instituto Invento, Diretor. E-mail: odascatolini@invento.org.br

${ }^{6}$ Embrapa Cerrados, pesquisador. Email: zare.soares@embrapa.br

7 Universidade de Brasília, estudante. Email: 190002450@aluno.unb.br

8 Universidade de Brasília, estudante. Email: 170110737@aluno.unb.br

Recebido em:

$11 / 05 / 2019$

Aceito para publicação em: 01/11/2019

Correspondência para: carolina.alzate@unb.br

\section{RESUMO}

As tecnologias sociais permitem a apropriação e a inclusão de agricultores e agricultoras, e o método de Construção da Capacidade Criativa (Creative Capacity Building) tem como objetivo desenvolver a capacidade de inovação e desenvolvimento tecnológico de baixo custo em comunidades. Essa abordagem pressupõe o envolvimento ativo dos atores desde seu desenho e construção, como a melhor forma de alcançar a apropriação tecnológica. Foram realizadas duas oficinas, utilizando-se essa metodologia em comunidades rurais que permitiram o desenvolvimento de diversos protótipos ligados a processos de transição agroecológica. Essa E- pesquisa procurou avaliar as expectativas e percepções sobre os impactos dessa metodologia sobre os participantes das oficinas e registrar seus desdobramentos. Foram aplicados questionários antes e depois das oficinas para os participantes. Embora as expectativas iniciais girassem em torno da realização de trabalhos em equipe, ao final, os participantes perceberam o desenvolvimento de habilidades como um insumo importante para desenhar e criar soluções apropriadas.

Palavras-chaves: Agricultura Familiar. Agroecologia. Tecnologia Social. Co-design.

\section{ABSTRACT}

Creative Capacity Building (CCB) is an approach to develop innovative capacity and low-cost technological development. CCB, as well as other social technologies, allows a greater inclusion and ownership by the beneficiary. This approach presupposes the active involvement of the actors and beneficiaries of technology in their design and construction as the best way to achieve technological appropriation. Two CCB workshops were held in Brazilian rural communities that allowed the development of several prototypes engaged to agroecological production. This research sought to evaluate the expectations and perceptions about the impacts of this methodology on workshop participants. Semi-structured questionnaires were applied before and after the workshops. Although initial expectations revolved around teamwork, in the end, participants realized the development of skills, in particular, to design and create low-cost solutions.

Keywords: Family Farmers. Agroecology. Social Technology. Co-design. 
Introdução

Grandes avanços na ciência, cultura e sociedade foram alcançados com o desenvolvimento tecnológico. Por outro lado, esse desenvolvimento trouxe, também, a compreensão do que é a produção de ciência e tecnologia, como elemento promotor da ação política dos usuários e representa elementos ativos da organização das relações humanas e com o seu ambiente (AKRICH, 2016).

Os aparelhos eletrônicos, o maquinário agrícola, os sistemas de comunicação e os painéis de energia fotovoltaica, são alguns exemplos de um universo expressivo de criações humanas que otimizam o trabalho e a vida das pessoas, bem como as conectam em torno de processos de criação e desenvolvimento tecnológico. Dado o impacto desse desenvolvimento na sociedade, a democratização do acesso às tecnologias é uma panaceia adotada por muitas políticas públicas como tentativa de reverter desigualdades e trazer soluções para os problemas cotidianos de populações mais vulneráveis. Contudo, muitas soluções se tornam ineficazes por negligenciar as idiossincrasias sociais, as preferências culturais ou mudanças de comportamento. Isso ocorre, principalmente, porque nas tecnologias convencionais há uma alienação entre a criação e o uso da tecnologia pelo seu beneficiário (BIJKER, 1994).

Ao pesquisar o nível de apropriação de painéis fotovoltaicos por comunidades no Gana, Quênia e Zimbábue, Bawakyillenuo (2012) notou que há uma certa variação de acordo com os grupos sociais. Ele percebeu que, quando o desenho não é conhecido pelo usuário local, abre a possibilidade de diversas formas de interpretação e relação com a tecnologia, que vai interferir na intensidade do seu uso e apropriação (PINCH e BIJKER, 1984). Além disso, a aceitação de uma tecnologia alóctone, transferida, pode ser prejudicada pela falta de conhecimento dos usuários em relação aos seus propósitos e potencialidades. Yuan e colaboradores (2011) concluíram que algumas comunidades chinesas que receberam sistemas solares percebiam essa tecnologia como negativa e limitada em termos de utilidade, capacidade de armazenamento e potência. Alguns estudos demonstram que a falha na difusão de algumas tecnologias está ligada, principalmente, à falta de atenção aos fatores locais, aos interesses e às reais necessidades (AVGEROU, 2008; BAWAKYILLENUO, 2012). Também se reportam revisões de estudos sociais da ciência e da tecnologia que adensam as correlações entre conhecimento, sociedade e tecnologia. Akrich (2016) analisa a experiência das pessoas, como ela se coloca, se mobiliza na produção do conhecimento, na política e como pode ser considerada como ciência.

Com o propósito de criar ferramentas e encarar as brechas mencionadas, emergiram abordagens baseadas na teoria de construção de tecnologia social (Social Construction of Technology SCOT), nos anos 1960, inicialmente com o intuito de envolver trabalhadores na criação dos seus próprios ambientes de trabalho (BIJKER, 1994).

No Brasil, os movimentos em torno da Tecnologia Social (TS) iniciam seu processo de consolidação com a criação do Marco Analítico Conceitual, em 2004 (FREITAS e SEGATTO 2012). O Instituto de Tecnologia Social conceitua TS como "um conjunto de técnicas, metodologias transformadoras, desenvolvidas e/ou aplicadas na interação com a população e apropriadas por ela, que representam soluções para inclusão social e melhoria das condições de vida" (ITS, 2004).

Dagnino (2004) destaca a importância de se conceber TS, principalmente, por dois fatores: existir uma tecnologia convencional excludente, com ênfase na maximização do lucro privado; e pelo fato das instituições de pesquisa ainda serem limitadas no desenvolvimento de tecnologias capazes de viabilizar a inclusão social. Portanto, podem ser norteadoras no processo de transformar o conhecimento científico e tecnológico em uma ferramenta de desenvolvimento da cidadania e para o avanço socioeconômico.

O Creative Capacity Building (CCB) é uma metodologia de design que tem como objetivo desenvolver a capacidade de inovação e desenvolvimento tecnológico de baixo custo nas comunidades. Os participantes entram em contato com o ciclo de desenho de tecnologias co-criadas desenvolvido pelo D-Lab/MIT (Massachusetts Institute of Technology) e IDIN (International Development Innovation 
Network). Nessa oficina, os participantes desenvolvem suas habilidades construtivas por meio da construção de tecnologias de baixo custo já existentes, ganhando prática no manuseio de diferentes materiais e ferramentas. Considerando aqui "habilidades", como colocado por Ingold (2010), como propriedades emergentes de sistemas dinâmicos que superam a dicotomia entre capacidades inatas e competências adquiridas, sendo que, nas oficinas, todas as pessoas têm as possibilidades de desenvolvê-las. Ao mesmo tempo, nas oficinas priorizam-se problemas que enfrentam em seu cotidiano, para os quais desenham e fazem protótipos de soluções tecnológicas de baixo custo apropriadas para a fabricação e uso no contexto local. Esse processo tem como objetivo melhorar a qualidade de vida e eficiência dos trabalhos cotidianos da comunidade, incentivar autonomia através da tecnologia de baixo custo, bem como possibilitar o melhor aproveitamento dos recursos disponíveis (NEDER e COSTA, 2014).

O Núcleo de Agroecologia da Universidade de Brasília (NEA/UnB) vem atuando desde 2016 em diversos territórios do Distrito Federal, Goiás e Minas Gerais. Ao pesquisar a relação entre segurança hídrica, alimentar e energética de famílias em assentamentos rurais, o Núcleo promove ações de extensão baseadas nas demandas identificadas nos territórios. Uma das dimensões da atuação do $\mathrm{NEA} /$ UnB é a inovação que, por meio da reflexão na TS, busca co-construir soluções para as contingências locais. Para tal objetivo, o CCB foi a metodologia adotada pelo NEA/UnB num trabalho em redes institucionais, junto ao Instituto Invento de tecnologias apropriadas para sustentabilidade, a Embrapa e o Centro de Inovação de Tecnologias Apropriadas e Educação, C-Innova, da Colômbia.

Também dentre os objetivos dos CCB realizados e como sendo esses momentos parte de um projeto em parceria com comunidades rurais, está o de promover a agroecológia, dentre outras estratégias, co-criando tecnologias de baixo custo de especial utilidade para este fim. Assim, este artigo traz elementos de análise de duas comunidades rurais. Dois assentamentos localizados em Planaltina/DF e Paracatu/MG, sendo que a parceria foi estabelecida junto às organizações socioprodutivas dos assentamentos representados pela Aprospera (Associação dos Produtores Agroecológicos do Alto São Bartolomeu) e pela Cooperfan (Cooperativa Mista dos Assentados e Agricultores Familiares do Noroeste de Minas Gerais).

Ambos sistemas se encontram em transição agroecológica em menor ou maior grau. Não foi objeto deste artigo analisar o grau de transição, apenas inserir o componente de cocriação de tecnologias que potencializem esse processo.

Em setembro de 2018 o NEA UnB, junto com as instituições parceiras mencionadas, realizaram oficinas CCB nas duas comunidades apresentadas. A primeira, no assentamento rural Nova Lagoa Rica, situado no noroeste de Minas Gerais, no município de Paracatu, com colaboração da Cooperfan. No mesmo mês aconteceu a segunda versão no Assentamento rural Oziel Alves III, situado na região administrativa de Planaltina (RA VI), na sede da Aprospera e em colaboração com a mesma. As oficinas contaram com a participação de, aproximadamente, 100 pessoas entre colaboradores, visitantes, palestrantes e participantes efetivos. Foram certificados 52 participantes, dentre comunitários e parceiros, que participaram das palestras e atividades até o desenho e desenvolvimento dos protótipos.

Observou-se, nas variações de expectativas, que o sistema produtivo das famílias pertencentes à Aprospera demanda tecnologias apropriadas para aumento da escala de produção, uma vez que já estão inseridos em redes de circuitos curtos de mercado onde a proximidade entre consumo e produção reflete sobre um maior esforço para a garantia de alimentos produzidos a partir do referencial da agroecologia. Já em assentamentos ligados à Cooperfan, na região de Paracatu/MG, encontra-se um estágio inicial de capacitação e sensibilização das famílias para adoção de práticas mais sustentáveis. Diagnosticou-se, nessa realidade, uma forte demanda para trocas de experiências para aprendizados em práticas agroecológicas.

Uma avaliação da aceitação e do potencial de tal metodologia para os objetivos propostos mostra-se necessária, para entender com mais profundidade os processos gerados pela iniciativa e assim direcionar ações nos territórios. Porém, projetos participativos são geralmente difíceis de avaliar devido à grande diversidade de abordagens e variáveis que apresentam (DRAIN et al., 2018). 
O objetivo deste artigo é avaliar a abordagem CCB, por meio da análise de expectativas e percepções de duas comunidades rurais nas quais foram desenvolvidas as oficinas, entre setembro e outubro de 2018. Para tal objetivo, o artigo adota a proposta de Drain e colaboradores (2018) para avaliar os resultados, baseada na análise de três componentes: visão, como uma aproximação às dinâmicas de construção do conhecimento; soluções, como os resultados obtidos em geração de artefatos físicos e mudanças nos processos; e, finalmente, empoderamento no âmbito político, na inclusão social, na capacidade criativa e no treinamento técnico.

\section{Métodos}

Foram utilizadas metodologias qualitativas de pesquisa, que tiveram como fonte de informação 62 questionários com as(os) participantes dos CCB, sendo 29 participantes da oficina realizada no Assentamento Oziel Alves 3, em Planaltina, Distrito Federal e 33 em Paracatu, Minas Gerais. Também foram realizadas observações em campo feitas pelas(os) mesmas(os) autoras(es) do texto que, ao mesmo tempo, facilitaram as oficinas; fotografia e vídeo dos processos e resultados dos CCB. Foi utilizada análise de conteúdo (BARDIN, 1977) para acessar e compreender as informações dos questionarios.

\section{O contexto das comunidades rurais}

No município de Paracatu, MG, encontra-se a sede da Cooperfan. Essa cooperativa tem sua base social distribuída por seis municípios do Noroeste de Minas Gerais e promove a comercialização dos produtos da agricultura familiar da região. Sua criação foi parte de uma estratégia para viabilizar acesso a mercados para os produtos de transição agroecológica e orgânicos em processo de certificação por organização de controle social. Os cooperados realizam a comercialização no Programa Nacional da Alimentação Escolar (PNAE) e atuam na agenda de políticas públicas da agricultura familiar e desenvolvimento rural.

Os agricultores e agricultoras que compõem a base social da Cooperfan atuam em cinco arranjos produtivos representativos das atividades da agricultura familiar da região: frutas, tanto exóticas quanto nativas; hortaliças; aves caipiras para ovos e carne; leite; e panificados. Em algumas dessas atividades existem arranjos mais estruturados ao longo da cadeia, como processos de agroindustrialização, desenvolvimento de marcas e estratégias de comercialização. Já existem processos como agroindústrias de polpas de frutas; beneficiamento do leite e seus derivados; produção de hortaliças orgânicas e agroecológicas; e panificação.

Em Planaltina, DF, especificamente no território do Alto São Bartolomeu, encontra-se a Aprospera. A associação realiza um trabalho de organização social das(os) produtoras(es) orgânicas(os) e agroflorestais da região no fortalecimento de suas iniciativas e atua em projetos ambientais de restauração, como o Projeto São Bartolomeu Vivo e o Programa Água Brasil, na linha Produtor de Água na bacia do rio Pipiripau. A Aprospera conquistou premiações recentes como "Iniciativas Rurais Sustentáveis" da Secretaria de Meio Ambiente; Prêmio Celso Furtado do Ministério da Integração Nacional e menção de honra da Câmara Legislativa Distrital durante o evento AgroBrasília (2018), ao promover diretamente o lançamento de 10 CSAs - Comunidades que Sustentam a Agricultura. As CSAs são uma estratégia de economia solidária baseada na associação colaborativa entre agricultor e grupos de consumo, os coagricutlores, em que estes passam a apoiar diretamente a prática da produção agrícola em troca de cestas de alimentos. Atualmente, 16 grupos trabalham com CSAs nesse novo modelo de comercialização no território da Bacia do Rio Pipiripau.

\section{Metodologia de construção de capacidades criativas}

Desenvolvidas basicamente por oficinas que fomentam um processo de ciclos de desenho de tecnologias, As Creative Capacity Building (CCB), assim denominadas em inglês, foram realizadas em 
experiências que objetivam uma maior inserção em mercados com base em transição agroecológica. Tem como foco melhorar as condições de vida, criando ou adequando meios de produção, aumentando a segurança alimentar, hídrica e energética das famílias (IDIN, 2018).

A metodologia pretende possibilitar a solução de diferentes tipos de problemas, estimular a igualdade de gênero e geracional, além de criar novas oportunidades de negócios, permitindo a geração de receitas adicionais para a comunidade. $O$ ciclo de desenho (apresentado na figura 1 ) de uma tecnologia social, com base na abordagem do CCB, é iniciado pela identificação e demarcação de um problema relevante para a comunidade pelas(os) mesmas(os) comunitárias(os), em seguida, vem a etapa do "conhecimento", com a realização de pesquisas e busca de informações para melhor demarcar o problema identificado. Na sequência, vem a etapa de "geração de ideias", na qual o grupo de trabalho gera ideias que são modeladas, debatidas e experimentadas, até que seja escolhida a ideia mais factível e adequada ao contexto cujos detalhes passam, então, a ser trabalhados. A fase seguinte é a da "experimentação", em que o protótipo da tecnologia é fabricado e testado. O protótipo é, posteriormente, apresentado a outras pessoas, que vão opinar sobre o projeto, levando o grupo a buscar novas informações, reiniciando, assim, o ciclo de desenho (IDIN, 2018).

\section{O CICLO DE DESENHO}

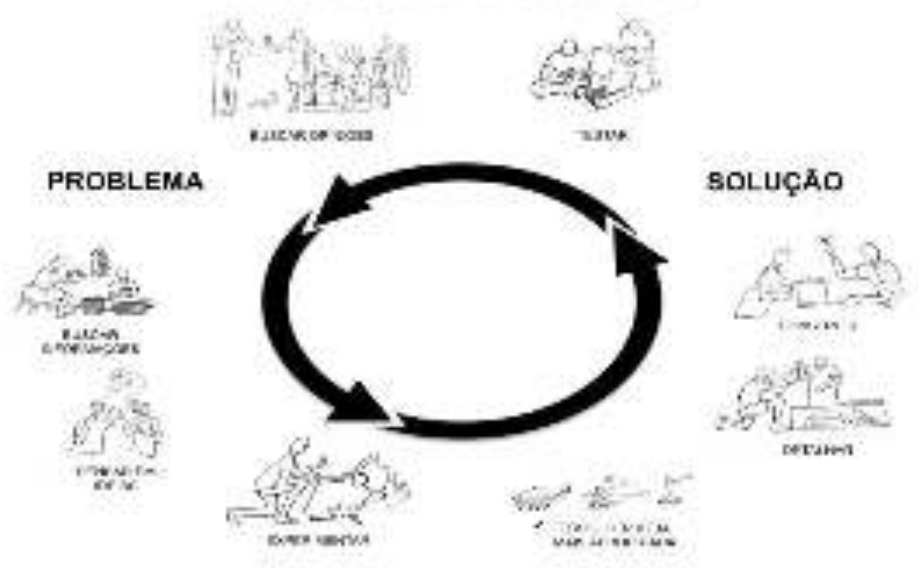

Figura 1. Ciclo de desenho utilizado nos CCBs

Nos eventos, as principais etapas dos ciclos de desenho e projeto foram colocadas em prática por representantes das comunidades, estudantes, técnicos e professores. Os participantes operaram ferramentas de construção, desenvolvimento, apropriação e adaptação social de tecnologias, na perspectiva da construção de inovações para fortalecer as estratégias e as trajetórias de sustentabilidade dos agricultores familiares.

Em Planaltina, participaram 22 pessoas, sendo 8 do gênero feminino. Em Paracatu, no assentamento Nova Lagoa Rica, participaram 30 pessoas, sendo 22 do gênero feminino. Os participantes foram representantes dos assentamentos Santa Rosa, Herbert de Souza, Tiro e Queda e Nova Lagoa Rica.

\section{Resultados e Discussão}

Em ambas as oficinas, consideradas para este artigo, foram aplicados questionários para avaliar a expectativa e a percepção dos impactos do CCB. Na seguinte tabela, se apresenta o tamanho e representatividade das amostras em cada oficina. 
Tabela 1. Amostra e representatividade dos participantes das oficinas de Creative Capacity Building (CCB) em Planaltina, DF e Paracatu, MG.

\begin{tabular}{lcccc}
\hline Comunidade & $\begin{array}{c}\text { Amostra formulário } \\
\text { inicial }\end{array}$ & Representatividade & $\begin{array}{c}\text { Amostra formulário } \\
\text { final }\end{array}$ & Representatividade \\
\hline Planaltina, DF & 11 pessoas & $50 \%$ & 8 pessoas & $36 \%$ \\
\hline Paracatu, MG & 18 pessoas & $60 \%$ & 25 pessoas & $83 \%$ \\
\hline
\end{tabular}

Com base nas dimensões de visão, soluções e empoderamento propostas por Draim (2018), foram desenhadas as perguntas nos formulários que respondem a cada uma das dimensões.

Tabela 2. Perguntas dos formulários relacionadas às três dimensões avaliadas quanto aos impactos das oficinas de "Creative Capacity Building" (CCB) nas comunidades estudadas.

\begin{tabular}{|c|c|c|c|}
\hline \multirow[t]{2}{*}{ Formulário } & \multicolumn{3}{|c|}{ Dimensões } \\
\hline & Visão & Soluções & Empoderamento \\
\hline Inicial & $\begin{array}{l}\text { Perguntas: } \\
\text { - Poderia, por favor, compartilhar por } \\
\text { que você decidiu participar do CCB? } \\
\text { - Por favor, termine a seguintes } \\
\text { frases: Para mim, o CCB será um } \\
\text { sucesso se... } \\
\text { - Quais atividades são valiosas para } \\
\text { você? (Múltipla escolha) } \\
\text { - Você, como você entende a co- } \\
\text { criação } \\
\text { - Você acha que a co-criação pode ser } \\
\text { valiosa para as comunidades? }\end{array}$ & $\begin{array}{l}\text { Perguntas: } \\
\text { - Com que nível de confiança você } \\
\text { se sente para desenvolver as } \\
\text { seguintes atividades? (habilidades } \\
\text { com diferentes materiais são } \\
\text { citadas) }\end{array}$ & $\begin{array}{l}\text { Perguntas: } \\
\text { - O que você mais espera alcançar } \\
\text { até o final do CCB? } \\
\text { - O que você espera conseguir nos } \\
\text { meses seguintes a sua } \\
\text { participação no CCB? }\end{array}$ \\
\hline Final & $\begin{array}{l}\text { Perguntas: } \\
\text { - Você acha que a co-criação foi } \\
\text { valiosa para a comunidade com a qual } \\
\text { você trabalhou neste CCB? } \\
\text { - Conte-nos, o que você mais gostou } \\
\text { no CCB? }\end{array}$ & $\begin{array}{l}\text { Perguntas: } \\
\text { - Que habilidades e/ou } \\
\text { conhecimentos você ganhou ou } \\
\text { desenvolveu tendo participado } \\
\text { das oficinas do CCB? Por favor, } \\
\text { indique exatamente o que. } \\
\text { - Que tipo de apoio você } \\
\text { considera que seria importante } \\
\text { para a continuidade dos projetos? } \\
\text { - Outra coisa que queira } \\
\text { compartilhar ou formas de você } \\
\text { se envolver conosco no futuro? }\end{array}$ & $\begin{array}{l}\text { Perguntas: } \\
\text { - Por favor, compartilhe quais } \\
\text { aspectos do CCB foram mais } \\
\text { valiosos para você (múltipla } \\
\text { escolha) } \\
\text { - O que você acha que vai mudar } \\
\text { no seu dia a dia depois de ter } \\
\text { participado do CCB? Por favor, } \\
\text { explique } \\
\text { - Agora que você concluiu o CCB, } \\
\text { quais são suas principais metas } \\
\text { para os próximos } 12 \text { meses? } \\
\text { - Você planeja continuar } \\
\text { trabalhando no seu projeto do } \\
\text { CCB no futuro? }\end{array}$ \\
\hline
\end{tabular}

Fonte: adaptado de Draim et al. (2018)

Outros métodos foram, também, utilizados para analisar as dimensões avaliadas, como: observações em campo, fotografias e vídeos dos processos e resultados dos CCB. Na tabela 2 se relacionam as metodologias com as dimensões às quais respondem. Cabe reforçar que as(os) 
facilitadoras(es) das oficinas tiveram dois papeis simultâneos de facilitação dos processos e observação em campo que foi registrada ao longo das análises dos resultados do presente texto.

Tabela 3. Outras metodologias de pesquisa para analisar as três dimensões avaliadas quanto ao impacto da oficina de "Creative Capacity Building".

\begin{tabular}{|c|c|c|c|}
\hline \multirow[t]{2}{*}{ Metodologias } & \multicolumn{3}{|c|}{ Dimensões } \\
\hline & Visão & Soluções & Empoderamento \\
\hline Observações em campo & $\begin{array}{l}\text { O conhecimento foi capturado } \\
\text { por meio de observações do } \\
\text { processo de construção dos } \\
\text { protótipos }\end{array}$ & $\begin{array}{l}\text { Foram observadas as } \\
\text { percepções } \\
\text { participantes sobre os } \\
\text { protótipos e as tecnologias } \\
\text { apresentadas }\end{array}$ & $\begin{array}{l}\text { A informação foi coletada a partir } \\
\text { de entrevistas com } \\
\text { pesquisadoras(es) e técnicas(os) } \\
\text { que acompanham os processos } \\
\text { participativos das comunidades }\end{array}$ \\
\hline $\begin{array}{l}\text { Fotografia e vídeo } \\
\text { processos e resultados } \\
\text { da oficina }\end{array}$ & & $\begin{array}{l}\text { Foi realizado um vídeo } \\
\text { compilando os depoimentos } \\
\text { de vários participantes }\end{array}$ & \\
\hline
\end{tabular}

Dessa forma, as questões e respostas foram organizadas de modo a se alinhar com as dimensões propostas por Draim e colaboradores (2018), contudo, adaptadas para a visão ou expectativas das comunidades; as soluções alcançadas; e o empoderamento das pessoas.

Como colocado, no intuito de entender as percepções quanto às motivações, expectativas e conclusões sobre as oficinas de CCB por parte dos participantes, foram aplicados questionários antes e após a realização destas. A partir das respostas dos questionários foi feita a análise do conteúdo.

A análise do conteúdo trata-se de um conjunto de técnicas de análise das comunicações. Essas técnicas visam obter, por procedimentos sistemáticos e objetivos de descrição do conteúdo das mensagens, indicadores que permitam a inferência de conhecimentos relativos às condições de produção/aceitação dessas mensagens (BARDIN, 1977).

No presente estudo, a análise de conteúdo foi feita através do método de análise por categorias temáticas, o qual visa encontrar uma série de significações detectadas por meio de indicadores que lhe estão ligados; codificar ou caracterizar um segmento e colocá-lo em uma das classes de equivalências definidas. As significações são criadas em função do julgamento do codificador que exige qualidades psicológicas complementares, como a fineza, a sensibilidade, a flexibilidade, para compreender o que importa no estudo, podendo variar de acordo com o objetivo deste (CAREGNATO e MUTTI, 2006).

A partir das respostas que dão luz sobre cada uma das três dimensões avaliadas, construímos as categorias conforme os temas que se manifestavam no texto, identificando o que há de comum no conteúdo de cada resposta, para permitir seu agrupamento em determinada categoria. Desta forma, no presente estudo, foram definidas as seguintes categorias: intercâmbio de conhecimento, soluções em tecnologias de baixo custo, trabalho em equipe e comunidade, autonomia e desenvolvimento de habilidades.

A dimensão "visão" foi abordada como a relação entre as expectativas das(os) participantes das oficinas de CCB com as dinâmicas de construção de conhecimento. A motivação para a troca de novos conhecimentos e a forma de abordá-los em comunidade foram os critérios que guiaram a análise dessa dimensão. Esses critérios foram escolhidos pela equipe organizadora das oficinas já que representam pontos de interesse para um trabalho a longo prazo com as comunidades.

A pergunta a seguir foi a única analisada em conjunto. Assim, a Figura 2 reflete a totalidade das motivações de ambas comunidades para participar das oficinas. 


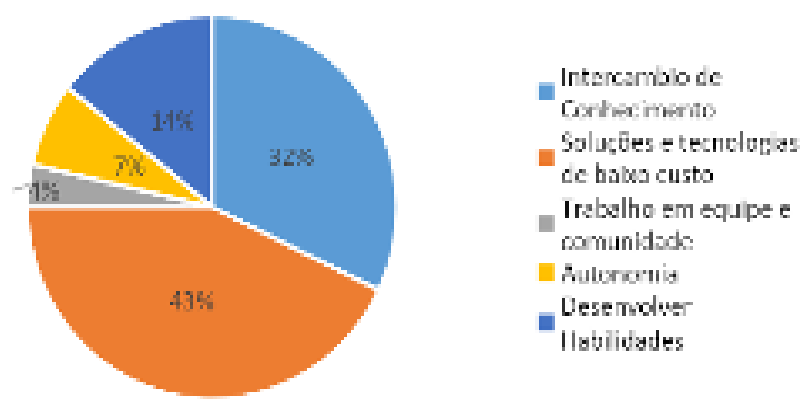

Figura 2. Respostas categorizadas das duas comunidades para a pergunta: Por que decidiu participar do CCB?

Como é possível observar, a motivação principal para a participação se baseia no interesse em desenvolver soluções e tecnologias de baixo custo. Nas observações em campo também se ratificou o alto interesse em desenvolver esses tipos de tecnologias e replicá-las nas propriedades produtivas das famílias. A segunda motivação citada, intercâmbio de conhecimento, se relaciona com o interesse em obter conhecimento novo e em poder compartilhar técnicas e habilidades anteriormente desenvolvidas. A terceira motivação se refere ao interesse por desenvolver habilidades, o que, também, pode ser observado em campo, já que, durante a oficina, houve grande participação de todas(os) nas atividades práticas de aprendizagem de habilidades. As outras motivações como trabalho em equipe e autonomia não apareceram tão relevantes nos questionários aplicados no início dos CCB.

a. O CCB será um sucesso se.... (Formulário inicial]

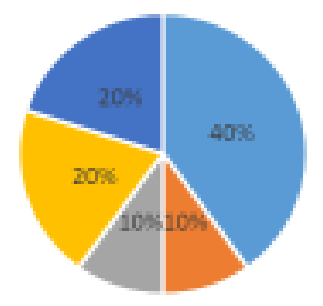

E Intertambia de Canhecimente

e Solupóes e tecnolopias de baino custo

in Trabalho em equipe ecomunidade

IIItanemik

a Desenvolver Habilidades b. o que wace rnais gos lou na CCD? \{Forrusalario $\mathrm{f}$ กล\}

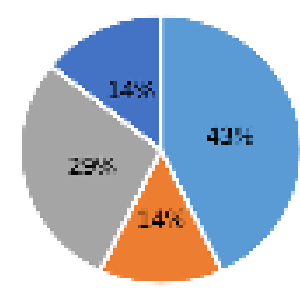

E Irtercimbo da carhecinento

Es Soluçōes a :ecolog as ce baivo custo

ntrabalia am aqulipe comunicace

II Rutanom:

E Leserveluser rabilidader

E.itros

Figura 3. Respostas categorizadas de participantes da oficina de Planaltina.

As respostas comparativas refletem um crescente interesse no trabalho em equipe e temas relacionados com a comunidade na comunidade no CCB de Planaltina, ao mesmo tempo que os interesses relacionados com autonomia diminuíram. 


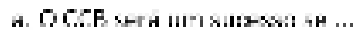

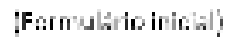

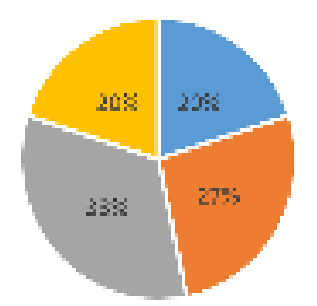

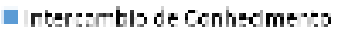

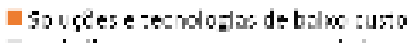

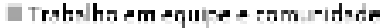

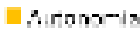

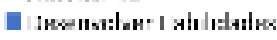

t. a cue wece mals zestounc CCB: |Fomul:ristrali

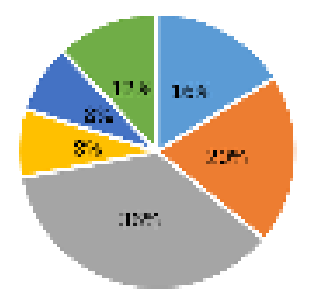

Im:enco-bo de ocn-edme-be

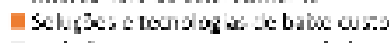

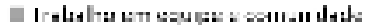

maris-n-is

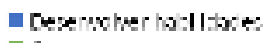

$0.5 x$

Figura 4. Respostas categorizadas de participantes do CCB Paracatu.

Por sua vez, no CCB de Paracatu, as respostas refletem uma diminuição no interesse pelo tema de autonomia e intercâmbio de conhecimentos para dar lugar a outra diversidade de interesses, que foram categorizados como "outros". Na categoria de outros, foram classificadas respostas referentes a interesses pela metodologia trabalhada, respostas que abrangiam mais de três categorias e respostas que faziam referência ao desempenho das(os) facilitadores. $O$ trabalho em equipe continua sendo a categoria mais citada, antes e depois da oficina. Em campo as(os) autoras(es) puderam confirmar que só com uma exceção, a dinâmica dos grupos de trabalho foi chave para o desenvolvimento do protótipo, característica que se adjudicou ao histórico de cooperativismo, associativismo e formação de coletivos nas comunidades. Uma das respostas do formulário que pode reforçar o alto interesse das duas comunidades pelo trabalho em equipe é sobre se a co-criação foi valiosa para a comunidade, a totalidade das respostas em ambas comunidades foi de SIM. Vale esclarecer que este conceito de cocriação, entendido como um ato de criatividade coletiva para a criação de soluções (SANDERS e STAPPERS, 2008), foi discutido em vários momentos nas oficinas.

Dentre os principais relatos dos participantes, podemos destacar as expectativas da oficina ser uma oportunidade de despertar nos participantes "um mundo" de possibilidades. Uma entrevistada observou "que cada tecnologia social apresentada aos agricultores é uma nova descoberta, além do fato de que eles se veem capazes [de construir inovações]". A satisfação com novos conhecimentos adquiridos também ficou expressa na seguinte fala de um agricultor: "aqui todo mundo dá ideias e faz críticas construtivas. Esse trabalho coletivo, de fazer junto, de ajudar uns aos outros, foi uma coisa maravilhosa" e, também, de outra agricultora que desenvolveu, a partir de sua problemática, um semeador : "foi maravilhoso ver que sou capaz. Para mim, essa máquina é muito boa. Tenho problema na coluna, não conseguia plantar porque tinha que me abaixar, então pagava pela mão-de-obra. Agora, eu mesma poderei plantar um canteiro bem rápido. Se em um dia eu plantava meio canteiro, agora posso plantar três ou quatro com menos esforço, melhor qualidade e menos desperdício". O aprendizado de novas técnicas ficou revelado nas impressões de alguns entrevistados: "vi pessoas que nunca tinham soldado ou trabalhado com máquinas industriais. Em três, quatro dias, já estavam pondo a mão na massa".

Embora um dos objetivos do CCB seja a própria co-criação de tecnologias, também é de grande importância o processo de apropriação da metodologia para desenho de soluções. Assim, o foco na avaliação dos resultados obtidos em relação à dimensão de soluções é a geração de artefatos físicos e as mudanças nos processos. Nos formulários iniciais obteve-se informação sobre a sensação de confiança dos participantes em diferentes aspectos relacionados às categorias analisadas. Essa relação apresenta-se na Tabela 4, a seguir. 
Tabela 4. Relação das categorias avaliadas com aspectos questionados no formulário inicial.

\begin{tabular}{ll}
\hline Categorias & Aspectos relacionados \\
\hline Desenvolver Habilidades & $\begin{array}{l}\text { Construir coisas com madeira } \\
\text { Construir coisas com metal } \\
\text { Construir coisas com outros materiais }\end{array}$ \\
\hline Trabalho em equipe e comunidade & Trabalhar em equipes que são diversas \\
\hline Autonomia & Coletar informações e feedbacks dos membros da comunidade \\
\hline Soluções e tecnologias de baixo custo & Definir claramente um problema \\
\hline Intercâmbio de informações & $\begin{array}{l}\text { Criar um solução junto com seus usuários em potencial (co-criação) } \\
\text { Trabalhar com materiais disponíveis localmente, fazendo as adaptações } \\
\text { necessárias }\end{array}$ \\
\hline
\end{tabular}

Os aspectos relacionados à mesma categoria foram agrupados e dispostos na Figura 5, onde se encontra o percentual de participantes que declarou estar confiante ou não confiante em cada um desses aspectos.

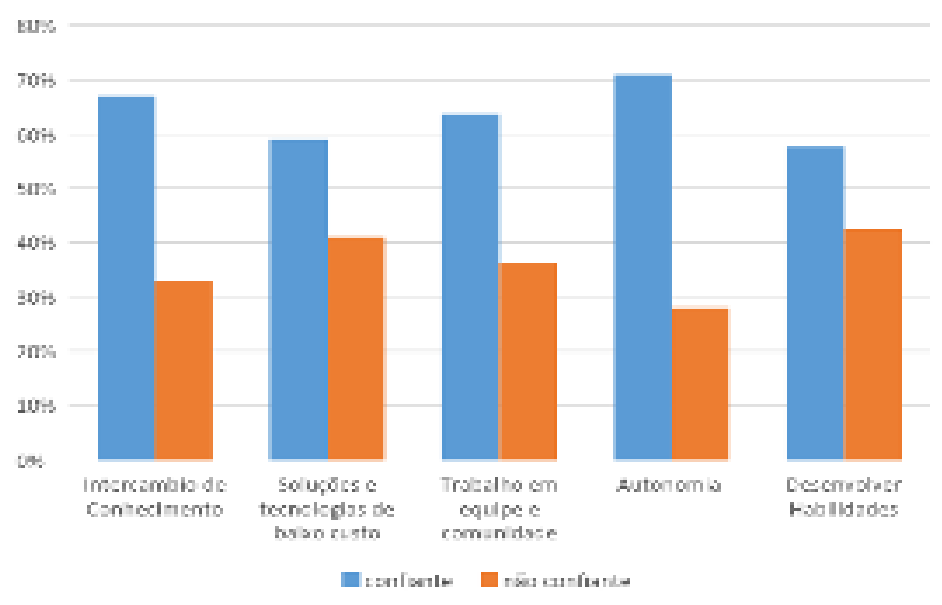

Figura 5. Sensação de confiança inicial de participantes em aspectos avaliados na oficina de Planaltina.

No formulário final se questiona sobre as habilidades e conhecimentos que os participantes adquiriram, as respostas também foram categorizadas (Figura 6).

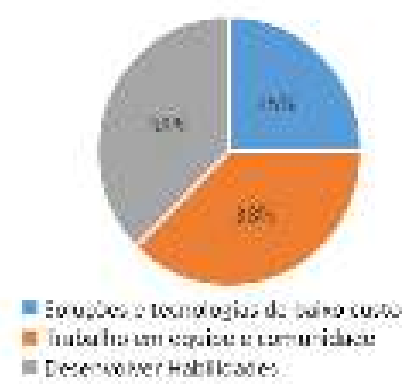

Figura 6. Respostas categorizadas sobre habilidades e conhecimentos adquiridos na oficina de Planaltina. 
Como observado na Figura 5, os aspectos que reportaram menos confiança por parte dos participantes antes do CCB Planaltina foram os relacionados ao desenvolvimento de habilidades. Porém, no formulário final, o desenvolvimento de habilidades foi a categoria mais frequente nas respostas que citaram aspectos relacionados. A categoria de trabalho em equipe se encontra presente tanto no início como no final da oficina, enquanto as soluções em tecnologias de baixo custo apresentavam umas das menores porcentagens em confiança antes do CCB e depois aparecem significativamente nas respostas finais.

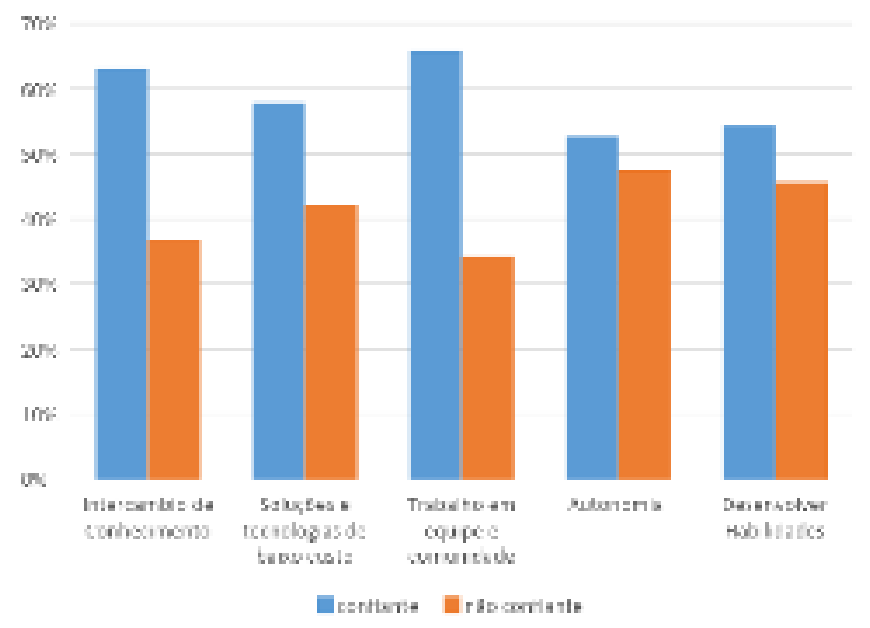

Figura 7. Sensação de confiança inicial de participantes em aspectos avaliados na oficina de Paracatu.
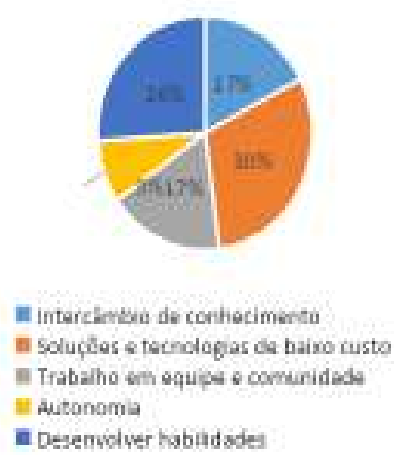

Figura 8. Respostas categorizadas sobre habilidades e conhecimentos adquiridos na oficina de Paracatu.

Pode se observar o contraste na sensação de confiança inicial relacionada a soluções e tecnologias de baixo custo e a frequência com que essa categoria foi citada como conhecimentos adquiridos neste aspecto. Também é notório o contraste entre o desenvolvimento de habilidades, inicialmente uma das categorias sinalizadas como a de menor sensação de confiança e no final foi a segunda categoria mais citada como aspecto adquirido durante o CCB em Paracatu.

Sobre os resultados das oficinas, nota-se que houve apropriação por parte dos envolvidos, tanto das tecnologias prévias construídas a partir da orientação das(os) facilitadoras(es) como as tecnologias construídas com base no próprio desenho dos participantes. Foi possível verificar a crescente motivação e participação no decorrer das oficinas. Observou-se a adesão de outras pessoas das comunidades após o início.

Os primeiros protótipos, como um debulhador de milho, prensa de briquetes de carvão, bomba d'água manual, caixas e iscas PET para meliponicultura e carregador solar para celular, foram construídos com peças de madeira, plástico e metal e seu desenho e instruções foram repassados pelas(os) facilitadoras(es) aos participantes. Este momento inicial é para reconhecimento dos chamados artefatos construtores de habilidades e são produtos de oficinas anteriores que servem para introduzir os primeiros estímulos às práticas de habilidades de construção. Os três protótipos desenhados e 
prototipados pelos próprios participantes em Planaltina foram: uma máquina motorizada que descasca, rala, corta e lava mandiocas, favorecendo o aproveitamento integral das raízes; uma semeadora manual para hortaliças como cenoura, beterraba e rabanete, que pode ser operada com a(o) agricultor(a) em pé ou sentada(o); e um coletor e carregador de capim roçado para cobertura de canteiros de hortas, implemento que pode ser acoplado a um pequeno trator.

Em Paracatu foram realizados cinco protótipos: um sistema coletor de água de chuva com sistema que descarta a primeira leva de águas sujas, um descascador de baru, uma bomba d'água eólica, um biodigestor para a produção de gás de cozinha a partir de esterco bovino e suíno, e uma prensa de queijo que consegue prensar 6 queijos por vez. Na Figura 9 estão destacados (a) um descascador de mandioca, desenvolvido em Planaltina e (b) bomba d'água movida a energia eólica, feito em Paracatu.

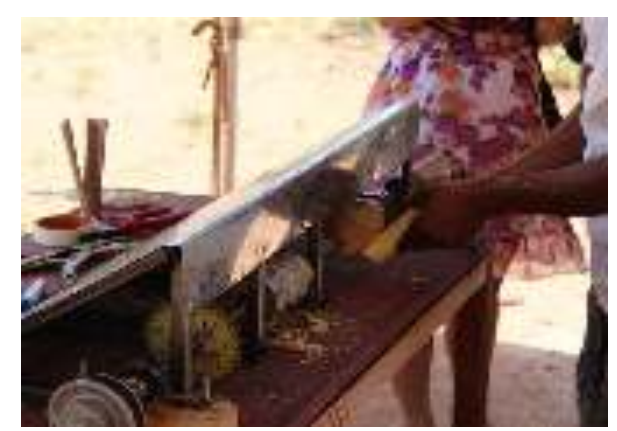

a. Descascador de mandioca - CCB Planaltina.

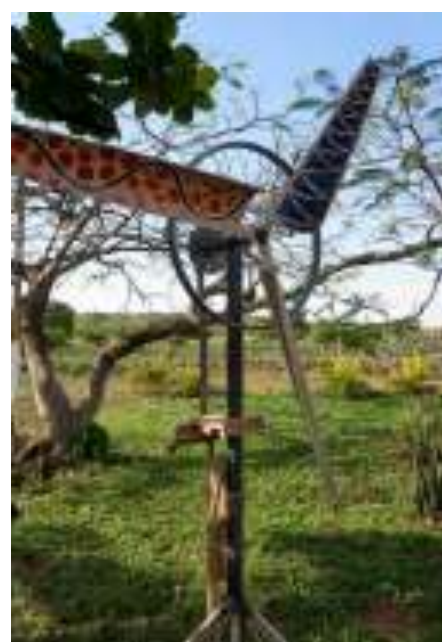

b. Moinho eólico - CCB Paracatu

A dimensão "empoderamento" foi analisada no âmbito da iniciativa comunitária, a inclusão social e a capacidade criativa. Em Paracatu, após a realização das oficinas de CCB, agricultoras(es) demonstraram interesse e apropriação do processo de desenho. A seguir, descrevem-se três processos.

As lideranças comunitárias demandaram da equipe responsável pela realização do CCB novos encontros para pensar juntos um plano de inovação que incluísse alguns dos protótipos construídos no CCB. O resultado dessa demanda foi que pesquisadoras(es) da Embrapa Cerrados, em parceria com a Cooperfan, iniciaram ações em projeto apoiado pelo CNPq. As ações principais do plano são a realização de novas oficinas focadas na adaptação dos protótipos desenvolvidos nos CCB para a sua implantação nas propriedades das(os) agricultoras(es) e na sua implantação como unidades de aprendizagem de tecnologias úteis para produção e processamento de frutas, sistema de baixo custo para produção de aves caipiras, adaptação e replicação do biodigestor para geração de energia e um sistema de coleta, armazenamento e irrigação de água para produção de frutas e hortaliças a partir dos protótipos da bomba eólica e do sistema de captação de água de chuva desenvolvidos no CCB.

A evidência de que houve apropriação na comunidade foi a observação da experiência de um dos participantes que continuou a etapa do "ciclo de desenho" de um dos protótipos, o cortador de barú, aproveitando-se das habilidades aprimoradas na oficina e a experiência com o primeiro protótipo para continuar a produção de outros cortadores. A inovação não só se reflete no artefato, mas também na forma de economia solidária que utiliza para comercializar o artefato, pois ele entrega um cortador de barú em troca de aves caipiras, gerando uma economia não monetária da replicação das tecnologias.

A efetividade da metodologia de co-criação de tecnologias e desenvolvimento de capacidades criativas expressa-se, também, no ensino. Assim, aponta-se para criação de disciplinas na universidade de Brasília e promoção de visitas de estudantes até a comunidade para conhecer o processo e os 
protótipos. A ideia do acompanhamento é que esses estudantes de engenharia de produção adotem algum dos protótipos e, junto com os participantes do CCB, realizem mais um ciclo de desenho para aprimorar alguns dos artefatos prototipados durante o CCB.

Em Planaltina também se identificaram processos de iniciativa comunitária da Aprospera após o CCB como:

Novas etapas de oficinas na Bacia do Rio Pipiripau, envolvendo, também, outras comunidades da região, com enfoque específico, dentre outros temas, na co-criação de tecnologias apropriadas para a coleta e beneficiamento de sementes nativas do Cerrado, demanda das comunidades locais para seus projetos de recuperação ambiental e para a geração de renda, assim como para o desenho de sistemas produtivos agrobiodiversos mecanizáveis.

No que se observou, no acompanhamento das ações foi a receptividade das comunidades no trabalho com a co-criação de tecnologias, o interesse na troca de conhecimentos e no desenvolvimento de habilidades. Esse processo vem sendo fortalecido pela ampliação da rede de facilitadoras(es) para replicar a metodologia em suas próprias comunidades, ampliando, dessa forma, a dimensão "empoderamento", um dos objetivos metodológicos das oficinas. Foi realizado um curso para formar facilitadoras(es) e um dos agricultores participantes no CCB Planaltina foi convidado pelas instituições organizadoras para realizar o curso de formação em julho de 2019. Essa formação foi realizada conjuntamente com um CCB em Mambaí, outra área de atuação do NEA.

Quanto à dimensão "inclusão social", partiu-se da priorização de trabalho em assentamentos rurais, envolvendo, especificamente, agricultoras(es) familiares que se encontram em algum grau de transição agroecológica. Segundo estabeleceu-se em um dos ambientes de interação multi-institucional da metodologia, no Núcleo de Agroecologia, a proposta foi incluir, pelo menos, 30\% de jovens e $50 \%$ de mulheres como participantes. A partir desse critério, foram revisadas as informações coletadas sobre participantes dos dois CCBs.

Tabela 5. Participação de mulheres e jovens nas oficinas de Creative Capacity Building (CCB).

\begin{tabular}{lcc} 
& Jovens & Mulheres \\
\hline CCB Planaltina & $27,3 \%$ & $45,4 \%$ \\
\hline CCB Paracatu & $15,8 \%$ & $78,9 \%$ \\
\hline
\end{tabular}

Como reportado na tabela, a participação de jovens não alcançou o objetivo formulado em nenhum dos locais, ainda que em Planaltina a participação tenha sido maior. Esse perfil de participação, na qual a juventude não representa uma cota significativa, pode responder ao fenômeno levantado desde décadas atrás e cada vez mais citado, de êxodo e envelhecimento rural (ALVES; DAYRELL, 2015; BRUMER, 2007; CAMARANO; ABRAMOVAY, 1999). Já a participação das mulheres teve uma maior expressão quantitativa. Uma análise sobre esses números poderá ser feita futuramente, uma vez que é notório o crescimento maior no envolvimento de jovens, contudo, ainda sem dados que possam trazer evidências para uma análise mais aprofundada. Depoimentos de mulheres reconhecendo a utilidade das habilidades novas que adquiriram nas oficinas mostram as percepções de si mesmas como "inventoras" e "construtoras".

Na dimensão "capacidade criativa" as(os) participantes foram indagadas(os) sobre os seus planos em relação a projetos ou inovações a partir do CCB. A categorização das respostas mostra-se no seguinte gráfico da Figura 10. 

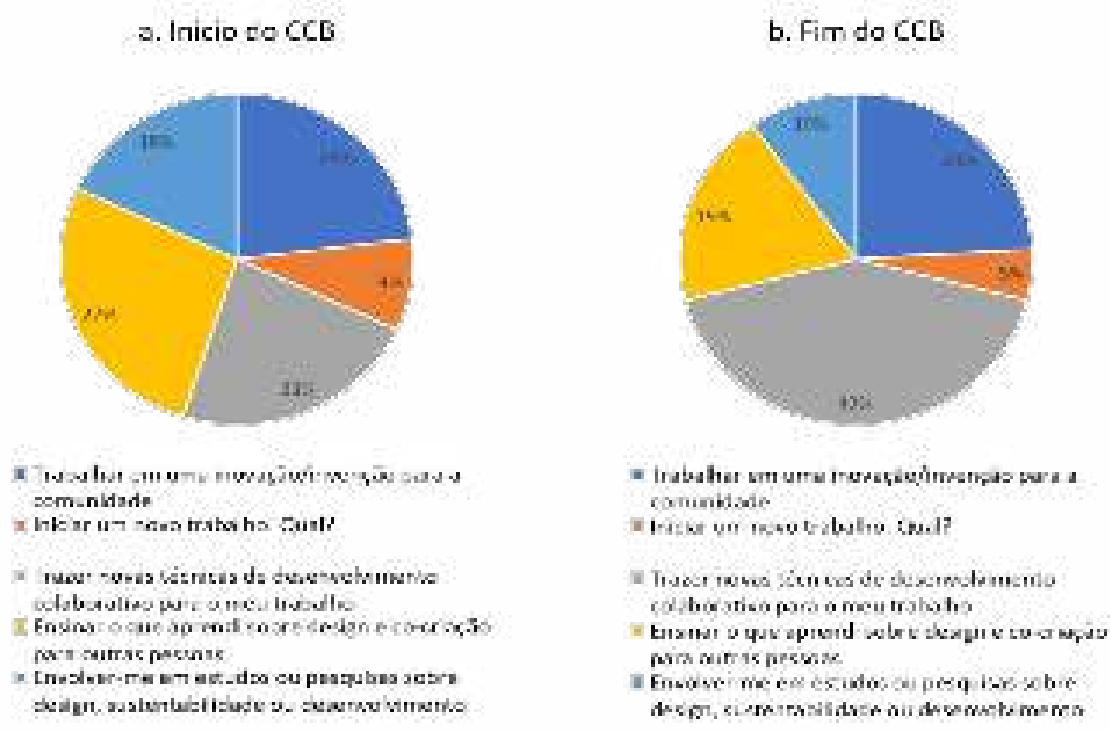

Figura 10. Planos dos participantes em relação às oficinas de Creative Capacity Building (CCB) da Aprospera (Planaltina, DF).

Como observado no gráfico, antes e depois do $\mathrm{CCB}$, o maior interesse baseou-se na utilização de novas técnicas de desenho colaborativo no dia a dia, notando-se que, no final do CCB, esse interesse quase duplicou. Diminuiu o interesse na replicação do ensinamento sobre co-criação e no aprofundamento de estudos e pesquisa sobre design. Manteve-se o interesse de trabalhar numa invenção ou projeto para a comunidade como segunda opção.

Os dados refletidos nos gráficos são coerentes com as observações em campo e depoimentos dos participantes. O interesse maior registrado foi na metodologia como nova técnica de desenho para pensar problemas do dia a dia e para inovar com projetos que beneficiem a comunidade.

s. Inicia to $\mathrm{CCO}$
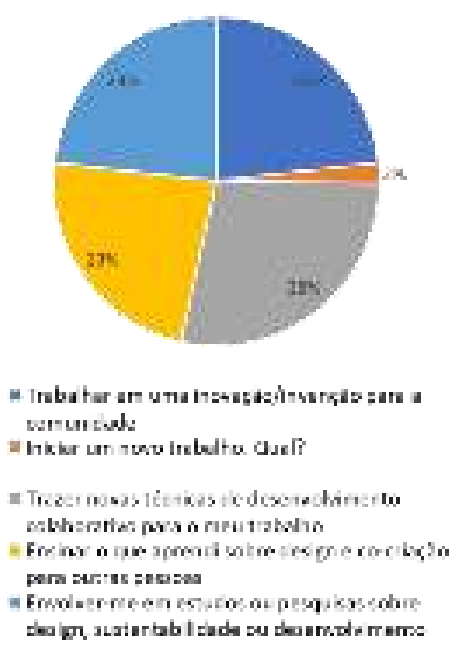

b. Firr do $C C B$
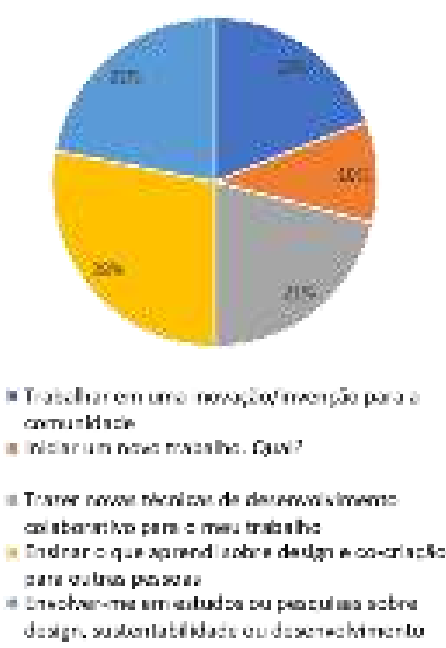

Figura 11. Planos dos participantes em relação às oficinas de Creative Capacity Building (CCB) de Paracatu, MG.

Já em Paracatu, as porcentagens das respostas não mostraram variações significativas. Aumentou o interesse em trabalhar nas áreas de desenho e desenvolvimento. Da mesma forma que em 
Planaltina, um dos pontos de maior interesse reportado foi o de utilizar novas técnicas de desenho colaborativo no dia a dia, mas o outro ponto de maior interesse foi o de ensinar outras pessoas o que foi aprendido sobre desenho e co-criação.

De acordo com depoimentos e, também, pelo perfil da população nos dois lugares, se explica que a preocupação de levar o conhecimento para outras pessoas se deva ao fato dos participantes pertencerem a diferentes assentamentos e estarem representando os mesmos. Por sua vez, em Planaltina, todos os participantes pertencem à mesma associação e regularmente se reúnem para diversas atividades.

Percebeu-se que houve intercâmbio de conhecimento e, inclusive, aperfeiçoamento dos facilitadores, externos à comunidade, através desse intercâmbio. As duas experiências deram uma bagagem muito importante no crescimento em técnicas e princípios da educação com adultos. A metodologia foi aperfeiçoada a partir das experiências relatadas. As inovações co-criadas nas oficinas são, hoje, referência para poder trabalhar em outras comunidades e enriquecer outros processos que busquem garantir segurança hídrica, energética e alimentar nas comunidades.

Outras experiências na América Latina estão sendo disseminadas, apesar de serem poucas sistematizações ou publicações sobre as experiências. Uma das publicações foi a da Corrales (2019), que relata quatro experiências de sucesso no Estado de Oaxaca, no México, onde também se identificaram vantagens nos processos gerados nas oficinas: autonomia, empoderamento no desenvolvimento de habilidades e a possibilidade de utilizar processos participativos neste tipo de atividades.

\section{Considerações Finais}

Baseadas na premissa de que qualquer pessoa pode se tornar uma criadora ativa de tecnologias e não apenas uma usuária dela, atividades como o CCB surgem como um método para alcançar uma apropriação tecnológica mais efetiva, em especial, por populações mais vulneráveis. A troca de conhecimentos permitiu pensar soluções para as atividades agroecológicas e um maior empoderamento dos participantes, bem como, proporcionou o ganho de conhecimento aos facilitadores sobre as técnicas de CCB. Embora as expectativas iniciais girassem em torno principalmente em realizar trabalhos em equipe, ao final, os participantes perceberam o potencial do desenvolvimento de habilidades para desenhar e cocriar soluções de baixo custo que permitem atender às suas demandas diárias e específicas. O CCB contribuiu com o despertar da criatividade na ação de adaptação social de tecnologias relevantes para uma transição agroecológica, considerando o enfoque dado nas oficinas facilitadas. Esses resultados permitem assinalar a metodologia de CCB como uma ferramenta que consegue abranger os princípios da Tecnologia Social. Identificou-se a necessidade de desenvolvimento de uma etapa posterior de adaptação dos protótipos e da avaliação posterior da sua efetividade, apontando para novas rodadas no ciclo de desenho para o seu aperfeiçoamento.

\section{Agradecimentos}

Este artigo foi construído por uma ampla rede de colaboradores ligados ao Núcleo de Agroecologia da Universidade de Brasília. Agradecemos à Fundação de Apoio e Pesquisa do Distrito Federal (FAPDF) e ao Conselho Nacional de Desenvolvimento Científico e Tecnológico (CNPq), que financiaram as atividades desenvolvidas nesta pesquisa; ao Instituto Invento, que organizou e facilitou as oficinas; ao C-Innova, especialmente ao Alex Freese e Martha Liliana Murcia, à Embrapa que participou em conjunto na organização do evento e, especialmente, à Aprospera e Cooperfan que aceitaram o desafio de sonharmos juntos

\section{Referências}

AKRICH, Madeleine. Inquiries into experience and the multiple politics of knowledge KEYNOTE PLENARY 1: TO WHAT EXTENT IS EMBODIED KNOWLEDGE A FORM OF SCIENCE AND TECHNOLOGY BY OTHER MEANS? 4S-EASST MEETING, BARCELONA, 2016 AUGUST 31ST. [s. I.], 2016 
ALVES, Maria Zenaide; DAYRELL, Juarez. Ser alguém na vida: um estudo sobre jovens do meio rural e seus projetos de vida. Educação e Pesquisa, [s. I.], v. 41, n. 2, p. 375-390, 2015.

BARDIN, L. Análise de conteúdo. Lisboa: edições, 70, 225. 1977

BAWAKYILLENUO, S. Deconstructing the dichotomies of solar photovoltaic (PV) dissemination trajectories in Ghana, Kenya and Zimbabwe from the 1960s to 2007. Energy Policy, 49, 410-421. 2012.

BIJKER, W. E. Sociohistorical technology studies. Handbook of science and technology studies/Sheila Jasanoff...[et al.], eds, 229-256. 1994

BRUMER, Anita. A problemática dos jovens rurais na pós-modernidade. Juventude rural em perspectiva. Rio de Janeiro: Mauad X, [s. I.], p. 35-51, 2007.

CAMARANO, Ana Amélia; ABRAMOVAY, Ricardo. Êxodo rural, envelhecimento e masculinização no Brasil: panorama dos últimos 50 anos. [s. I.], 1999.

CAREGNATO, R. C. A.; MUTTI, R. Pesquisa qualitativa: análise de discurso versus análise de conteúdo. Texto contexto enferm, 15(4), 679-84. 2006.

CORRALES, T. De Mexicanas a emprendimiento impulsado por la innovación. Sostenibilidad. 2019

DAGNINO, R. A tecnologia social e seus desafios. In: Lassance Jr. A. et al.(orgs). Tecnologia social: uma estratégia para o desenvolvimento. Rio de Janeiro: FBB, 216p. 2004.

DRAIN, Andrew; Aruna SHEKAR \& Nigel GRIGG. Insights, Solutions and Empowerment: a framework for evaluating participatory design, CoDesign, 2018 DOI: 10.1080/15710882.2018.1540641.

FREITAS, C. C. G., \& SEGATTO, A. P. (2012). TECNOLOGIA SOCIAL-CARACTERIZAÇÃO DA PRODUÇÃO CIENTÍFICA. Sustentabilidade e responsabilidade social,4, 31-45

IDIN. About IDIN. 2018. Disponível em: <http://www.idin.org/about-idin/our-approach>. Acesso em: 5 maio. 2019. INGOLD, Timothy. Da transmissão de representações à educação da atenção. Educação, [s. I.], v. 33, n. 1, p. 6-25, 2010.

ITS (Instituto de Tecnologia Social). (2004). Reflexões sobre a construção do conceito de tecnologia social. In: Lassance Jr. A. et al.(orgs). Tecnologia social: uma estratégia para o desenvolvimento. Rio de Janeiro: FBB, 216p.

NEDER, R. T., \& COSTA, F. M. P. (2014). Ciência, tecnologia, sociedade (CTS) para a construção da agroecologia, Universidade de Brasília. Serie I Cadernos de construção social da tecnologia.

PINCH, T. J., \& BIJKER, W. E. The social construction of facts and artefacts: Or how the sociology of science and the sociology of technology might benefit each other. Social studies of science, 14(3), 399-441. 1984.

SANDERS, Elizabeth B. N.; STAPPERS, Pieter Jan. Co-creation and the new landscapes of design. CoDesign, [s. I.], v. 4, n. 1, p. 5-18, 2008. Disponível em: https://doi.org/10.1080/15710880701875068 Acesso em: 5 maio. 2019.

YUAN, X., ZUO, J., \& MA, C. Social acceptance of solar energy technologies in China-End users' perspective. Energy policy, 39(3), 1031-1036. 2011. 